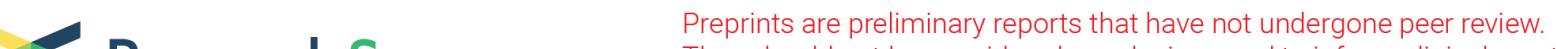 Research Square
They should not be considered conclusive, used to inform clinical practice,
or referced by the media as validated information.
}

\section{Extraction and Characterization of Fiber Treatment Inula Viscosa Fibers as Potential Polymer Composite Reinforcement}

\section{Moussaoui Nafissa}

Mohamed Boudiaf University of M'Sila Faculty of Technology: Universite Mohamed Boudiaf M'sila Faculte de Technologie

\section{Rokbi Mansour}

Mohamed Boudiaf University of M'Sila Faculty of Technology: Universite Mohamed Boudiaf M'sila Faculte de Technologie

\section{Osmani Hocine}

University of Setif 2: Universite Setif 2

\section{Mohammad Jawaid ( $\sim$ jawaid_md@yahoo.co.in )}

Universiti Putra Malaysia https://orcid.org/0000-0001-5348-5740

\section{A. Atiqah}

Universiti Kebangsaan Malaysia

\section{Mohammad Asim}

Universiti Putra Malaysia

\section{Benhamadouche Lamia}

Mohamed Boudiaf University of M'Sila Faculty of Technology: Universite Mohamed Boudiaf M'sila Faculte de Technologie

\section{Research Article}

Keywords: Inula viscosa, Chemical treatment, EDX, X-ray diffraction, Thermogravimetric analysis, Micro bond test, Surface characterization

Posted Date: February 24th, 2021

DOl: https://doi.org/10.21203/rs.3.rs-231207/v1

License: (c) (1) This work is licensed under a Creative Commons Attribution 4.0 International License. Read Full License

Version of Record: A version of this preprint was published at Journal of Polymers and the Environment on April 24th, 2021. See the published version at https://doi.org/10.1007/s10924-021-02147-w. 


\section{Abstract}

This research aims to analyze the newly discovered cellulosic fiber from the bark of Dittrichia viscosa, or Inula viscosa (IV), and evaluate the effects of permanganate and alkali chemical treatments on the physical properties to improve the interfacial bonding between Inula viscosa reinforced polymer composites. These permanganate and alkali treatments are both efficacious in helping in reducing hydrophilicity and eliminating impurities from the fiber surface, which has been confirmed by scanning electron microscope (SEM) observation, thermogravimetric analysis (TGA), X-ray diffraction (XRD), and Fourier Transform Infrared Spectrometry (FTIR). Permanganate-treated IVFs have shown higher tensile strength and interfacial stress resistance (IFFS) than alkaline IVFs, and untreated IVFs by tensile and droplet tests. The different characteristics were studied and compared with other bark fibers already available. It is estimated that the fiber treatments will enable high-quality IVF-reinforced polymer composites for use in the industry.

\section{Introduction}

Societal needs for new environmentally friendly materials make scientists to develop materials from nature itself. The increased numbers of research that working on renewable and biodegradable materials to replace conventional materials. [1-4]. Researchers and scientists are currently focusing on green composite materials from plants fibers with good fiber yields, cost-effective without compromising mechanical properties [5-7]. This is justified because, on the one hand, natural fibers have the status of renewable and durable materials; on the other hand, they are abundant, light, of moderate resistance, high specific modulus compared to synthetic ones [8-10]. Composite materials reinforced by natural fibers have contributed significantly to the human race's well-being and technological development. The construction industry, vehicle parts, domestic applications, aerospace, sports equipment, and others have been more inclined to use cellulosic fibers because of their benefits $[11,12]$.

The various sections of a plant, such as bark, root, seed, leaf can be obtained from the cellulosic fiber. The latter is one of the most available and inexpensive polymers on the planet due to its wide variety of industrial and common applications. When assessing natural fibers' properties, natural fibers properties are also highly influenced by the environment's growth, such as humidity, temperature, soil, and all affect fiber strength, density, and so on. Also, the fibers' extraction (chemical, mechanical, or biological technique) leads to a variation of the properties.

Generally, the plants containing natural fibers have different regions and conditions. It depends on the plant's age, place control and chemical fiber modification $[10,13]$. The cellulose's exceptional properties such as low spiral angle, small diameter, and continuous will enhance the properties of the composite. The outer layer of cellulose fiber is covered by non-cellulosic component (hemicelluloses, lignin, pectin, and wax). 
The conditions of the natural fiber are based upon the strength of cellulose fiber. Higher tensile strength is achieved by the chemical composition of the cellulose fiber. Therefore, it is necessary to explore new natural fibers, with the required strength properties of fiber reinforcement. A wide range of diverse natural fiber are available that offer reinforcing effects to polymer composites. The mechanical efficiency of polymer matrix composite is primarily dependent on the interfacial bonding. The fibers may be changed in chemical or physical treatments $[12,14]$. Also, natural fibers treated with mercerization, silane treatment, benzoylation, potassium permanganate, etc., have significant advantages, such as lower water absorption, increased surface roughness, and higher thermal stability, less amorphous content, improved crystallinity index, and increased crystallite size [15-17]. Natural fibers are obtained from various plants such as tree bark such as Azadirachta indica, Ceiba pentandra, Acacia Concinna, Grewia tilifolia, Acacia Nilatica L., Acacia leucophloea, ramie, and yarn have been a focus of research for scientists as reinforcements of composite because of their specific properties and availability [18-22]

The future research will investigate a new bark fabric Dittrichia viscose $L$ (Inula Viscosa) plant that has not been studied so far, despite its abundance in the Mediterranean region, Southeast Europe, and Asia West. In this study, two different chemical treatments, $3 \%$ alkaline and $3 \%$ permanganate, were adopted to modify the IV fibers samples of bark were harvested using an ecological technique. The physicochemical, morphological, mechanical and thermal properties of the IV fibers was investigated for the first time in this work. The fiber surface and fiber structure morphology were observed by using a binocular microscope and scanning electron microscopy (SEM).

The surface morphology of the new natural fiber was investigated using a binocular microscope and scanning electron microscopy (SEM). Infrared spectroscopy (FTIR) and X-ray diffraction (XRD) were employed to analyze the chemical and molecular structure of untreated and treated

IV fibers. In the TGA analysis, thermal stability was conducted to analyze both the untreated and treated IV fibers. This new cellulosic fiber's mechanical property was investigated using the single filament test according to the ASTMD3379 standard method. The interfacial shear strength (IFSS), post-debonding strength (tpost-debonding), and debonding behaviors were studied using a micromechanical droplet approach.

\section{Materials And Method}

\subsection{Materials}

Dittrichia viscose (L.) or Inula viscosa (IV) owes its name to the Greek "inaein" which means purged. This plant is known in Algeria as "Magraman". It is an undemanding plant in the Mediterranean region and widespread in northern Algeria. It grows in grassy places, in fields, and is also found along roadsides and paths. It belongs to the family Asteraceae, Class: Magnoliopsida; Genus: Inula Species: Inula viscosa. It is a wild, perennial, tap rooted, reasonably large (up to $1.50 \mathrm{~m}$ tall) plant. Its stems are fairly branched and have dense foliage. The leaves, alternate, elongate to lanceolate, are inserted directly on the stem, without 
petioles. The whole plant is coated with glandular hairs that release an odoriferous and sticky resin, with a smell of camphor, Figure 1.

\subsection{Fiber extraction from the plant}

Fresh Inula viscosa plant was collected from Hodna region (Algeria) in April 2019. The IVs' barks were submerged in a small water tap for five weeks to detach outer skin from the stalk by using biological retting technique, Figure $2(a),[23,24]$. Next, the innermost layer was manually removed from the outer layer. The inner layer of the bark yielded fine fibers. The extracted fibers were washed in running water to get rid of unwanted contaminants that were left behind the fiber surface, then dried in an oven at $70{ }^{\circ} \mathrm{C}$ for 6 hours, Figure 2 (b).

\subsection{Chemical treatments}

Two different chemical treatments were used in this analysis. The $3 \%$ alkaline and $3 \%$ permanganate were used to alter the Inula viscosa fibers' surface and to foster a stronger bonding between these fibers and the resin.

\subsubsection{Alkaline treatment}

IVFs were immersed in distilled water with a $3 \%$ sodium hydroxide solution, for 3 hours, at RT. The fibers were immersed in water prior to having neutral $\mathrm{pH}$ reached. After rinsing, the fibers were dried for 48 hours before being characterized.

\subsubsection{Permanganate treatment}

For the permanganate treatment, the pretreated with alkaline fibers as in Section 2.3 .1 were soaked in $3 \%$ of Potassium permanganate $\left(\mathrm{KMnO}_{4}\right)$ solution for 3 minutes [25]. These fibers were washed and dried in the air.

\subsection{Characterization}

\subsubsection{Scanning electron microscopy}

The surface morphology of untreated raw fibers, 3\% alkaline, 3\% permanganate -treated Inula viscosa fibers were analyzed using a scanning electron microscope (SEM) machine Model HITACHI S-3400N. The SEM instrument was set up at an emission current of $58 \mu \mathrm{A}$. The working distance was set to $6.2 \mathrm{~mm}$, and the acceleration voltage of $5.0 \mathrm{kV}$. The specimens were coated with a thin gold layer to avoid electrical charges during the examination.

\subsubsection{Energy-dispersive X-ray spectroscopy analysis (EDX)}

The EDX involves an analytical method was employed for the element analysis of a sample attached with SEM images. This approach allows elements from the whole element of periodic table to be detected 
of untreated, $3 \%$ alkaline, $3 \%$ permanganate treated IVFs, except for $\mathrm{H}, \mathrm{He}$, and $\mathrm{Li}$. Therefore, the Hydrogen can't be observed by this technique which represents the major constituents of natural fiber.

\subsubsection{Fourier Transform Infrared Spectrometry (FTIR)}

The FTIR analysis was carried out for untreated raw fiber, 3\% alkaline, $3 \%$ permanganate treated Inula viscosa fibers by using an FTIR machine (SHIMADZU81001, Japan). The purpose of using FTIR analysis to distinguish the changes in functional groups on the fiber surfaces of IVs. All spectra were recorded in the range from $4000 \mathrm{~cm}^{-1}$ to $500 \mathrm{~cm}^{-1}$. The sample preparation for this testing, the fibers were chopped and were ground into powder form.

\subsubsection{X-ray diffraction analysis (XRD)}

The degree of crystallinity and crystalline size of cellulosic fibers IVs were tested by using an X-ray diffraction test [1]. The XRD testing is non-destructive and rapid testing. The tests were carried out for the untreated raw fiber, $3 \%$ alkaline and 3\% permanganate-treated of IV fibers. In this testing, the Copper was used as the anode material with monochromatic $\mathrm{Cu}$ Ka radiation with a wavelength of $0.154 \mathrm{~nm}$ and a current of $30 \mathrm{~mA}$ and voltage of $30 \mathrm{kV}$. The continuous scanning mode, $2 \theta$ range varying from $5^{\circ}$ to $60^{\circ}$ with a step size of $0.02^{\circ}$ at $25^{\circ} \mathrm{C}$. The Segal empirical technique and Scherer's equation were used to determine, the degree of crystallinity and crystallite size of the untreated raw fiber, $3 \%$ alkaline and $3 \%$ permanganate treated- Inula Viscosa fiber as displayed in Equation (1) and (2).

$$
C I(\%)=\left(I_{c}-I_{a m}\right) / I_{c} \ldots \ldots \ldots \ldots . E q .(1) .
$$

Where, Ic represents the maximum intensity of the crystalline phase peak and $\mathrm{I}_{\mathrm{am}}$ represents the amorphous phase's intensity in the cellulose present in the fiber [26].

\section{$C S=K \lambda / \beta \operatorname{Cos} \theta \quad$ …........ Eq. (2).}

Where $K=0.89$ is Scherer's constant, $\beta$ is the peak's full-width at half-maximum, $\lambda$ is the wavelength of the radiation, and $\theta$ is the corresponding Bragg angle [27].

\subsubsection{Thermogravimetric analysis (TGA)}

The thermal stability and thermal decomposition of untreated raw fiber, $3 \%$ alkaline and $3 \%$ permanganate-treated IV fibers were obtained by using Thermogravimetric analysis by using GA machine Model (TGA Q 500 TA Instrument, USA). The specimens were measured under room temperature ranging from $30{ }^{\circ} \mathrm{C}$ to $600{ }^{\circ} \mathrm{C}$.

\subsubsection{Density measurement}


The density of the untreated raw fiber, $3 \%$ alkaline, $3 \%$ permanganate-treated IVFs was calculated by a liquid pycnometer for solids with immersion liquid known as the methanol (methanol, $\rho=791 \mathrm{~kg} / \mathrm{m} 3$ at $21^{\circ} \mathrm{C}$ ). The liquid pycnometer was based on direct measurement of specimen's volume. The accuracy of electronic weighing machine was checked at $0.00001 \mathrm{~g}$ before the weight measurement of the fiber. The sample of IVFs were cut with the length of $1 \mathrm{~mm}$ to suit in the pycnometer [28] and were placed in an oven at $60^{\circ} \mathrm{C}$ until the moisture content was reduced to below $5 \%$ before testing [29]. The densities of raw and treated IVFs ( $\rho I V F s$ ) were calculated through the following equation (3) [28]

$$
\rho_{I V F}=\frac{m_{2}-m_{1}}{\left(m_{\mathrm{s}}-m_{1}\right)\left(m_{4}-m_{2}\right)} \rho_{E} \quad \ldots \ldots \ldots \ldots . . . \quad \text { Eq. (3). }
$$

Where, $\rho_{\text {IVF }}$ is the density of IVFs $\left(\mathrm{kg} / \mathrm{m}^{3}\right), \rho_{E}$ is the density of methanol $\left(\mathrm{kg} / \mathrm{m}^{3}\right), \mathrm{m}_{1}$ is the mass of empty pycnometer $(\mathrm{kg}), \mathrm{m}_{\mathbf{2}}$ is the mass of pycnometer with fibers $(\mathrm{kg}), \mathrm{m}_{3}$ is the mass of pycnometer with methanol $(\mathrm{kg})$, and $\mathrm{m}_{4}$ is the mass of pycnometer with fibers and methanol $(\mathrm{kg})$.

\subsubsection{Diameter measurement}

A diameter test was carried out on a single fiber of untreated raw, $3 \%$ alkaline at $3 \%$ permanganatetreated at room temperature by using Olympus, BX51 optical microscope (Japan) with a magnification of $5 X$, three replicates were measured for each untreated and treated IV fiber by placing the fiber over a glass plate and taping down its end to obtain a clear image [30].

\subsubsection{Tensile test}

Tensile testing of untreated raw fiber, $3 \%$ alkaline and $3 \%$ permanganate-treated IVFs were evaluated by Instron universal testing machine (UTM) at a speed of $1 \mathrm{~mm} / \mathrm{min}$ according to ASTM D 30393. The fibers were then fixed and glued to the tab shape, which was performed with the gauge length of $30 \mathrm{~mm}$ fibers then inspected to remove the crack, Figure 3. The tensile strength of fibers was calculated from the following equation (4) [31].

\section{$T=F / A \quad$........... Eq. (4).}

Where, $\mathrm{T}$ tensile strength in $\mathrm{Pa}, \mathrm{F}$ force to failure in $\mathrm{N}, \mathrm{A}$ average fiber area in $\mathrm{m}^{2}$.

\subsubsection{Droplet test}

In the droplet test, a thin metal rod was chosen to place microdroplets of epoxy resin on single fibers that were fived to a paper frame and left to solidify. Before testing, the paper frame was cut away when a sample was connected to the tensile testing machine equipped of $5 \mathrm{kN}$ (INSTRON UTM). The interfacial shear strength (IFSS) which evaluate the adhesion in specific fiber matrix system according to the following equation (5) [32]

$$
\tau=\mathrm{F} \max /(\pi \mathrm{DL}) \quad \ldots \ldots \ldots \ldots \text { Eq. } \mathbf{E} \text { (5). }
$$


Where $\tau$ is the interfacial shear strength (MPa), $F_{\max }$ is the maximum pull-out force; $D$ is the fiber diameter and $L$ is the embedded length. Both parameters were measured using an optical microscope equipped with a high resolution before testing, Figure 4 (a). The schematics of the microdroplet test are shown in Figure 4 (b).

The ten samples for each untreated raw fiber, 3\% alkaline and 3\% permanganate-treated, were tested. The fiber diameter measurement was obtained from the point nearest to the droplet to both sides' fiber contacts.

\section{Results And Discussion}

\subsection{Density measurement}

Density measurement of the natural fibers is essential to evaluate the potential density of composite materials that use certain fibers. Various factors affect the density of cellulosic fibers such as the soil plant conditions, humidity present, fiber 's age, the fiber extraction process, etc.

The density value for $3 \%$ alkali and $3 \%$ permanganate treated was IVFs (1102 $\left.\pm 33.42 \mathrm{~kg} / \mathrm{m}^{3}\right),(1154 \pm$ $\left.13.22 \mathrm{~kg} / \mathrm{m}^{3}\right)$ which is a slight density increment compared to untreated IVFs $\left(1040 \pm 10.54 \mathrm{~kg} / \mathrm{m}^{3}\right)$. This is possibly attributed to the pores and voids in the fiber surface consisted grafted molecules during chemical treatments [33-35]. From this testing, it was noted that the density of novel fiber IV was lower than other natural fiber such as jute $\left(14800 \mathrm{~kg} / \mathrm{m}^{3}\right)$ [36], sisal $\left(1500 \mathrm{~kg} / \mathrm{m}^{3}\right)$ [37], Alfa and Sabra fibers $\left(1.40 \mathrm{~g} \cdot \mathrm{cm}^{-3} \pm 0.02\right)$ [34], banana $\left(1350 \mathrm{~kg} / \mathrm{m}^{3}\right)$ [38], Cyperus pangorei $\left(1102 \mathrm{~kg} / \mathrm{m}^{3}\right)$ [39]. Thus, IVs could be the candidate fiber reinforcement for composite lightweight.

\subsection{Diameter measurement}

The average diameters of the untreated raw fiber, $3 \%$ alkaline and $3 \%$ permanganate treated IVs fiber as shown in Figure 5. The diameter of untreated raw fiber $(93.50 \pm 2.75 \mu \mathrm{m}), 3 \%$ alkaline $(80.41 \pm 1.63 \mu \mathrm{m})$, and $3 \%$ permanganate treated $(78.60 \pm 1.82 \mu \mathrm{m})$., respectively.

\subsection{Scanning electron microscopy (SEM)}

The surface morphology of fibers can be determined using the Scanning Electron Microscopy (SEM) method to examine the surface morphology of fibers. Scanning electron micrographs of untreated, alkaline, and permanganate-treated fibers are presented in Figure 6. Figure 6 (a) shows the SEM micrograph of untreated fibers, the surface of IVs showed absence of impurities such as wax and grease, and internal fibrils [40]. At higher magnification, Figure 6 (b) shows that the removed waxes and oils from the fibers' surface were removed by $3 \%$ alkaline treatment, thus enable surface roughness on the fiber surface $[41,42]$. The alkaline treatment showed the differences compared to raw fiber. In this case, the fiber's surface was smoother than the raw fiber due to removing surface impurities. For permanganatetreated fibers, Figure 6 (c), it can be observed that the fiber became cleaner, with a rougher surface, as 
impurities were removed from the surface of the fiber [35]. This rough surface may improve interfacial bonding when IV fibers are used as reinforcing materials.

\subsection{Energy-dispersive X-ray spectroscopy analysis (EDX)}

The EDX technique relies on the sample's major interaction and the X-ray excitation source. The qualitative findings on the quantity of major elements (carbon, oxygen, calcium, manganese, etc.) provided by the fiber surface of untreated and treated IVFs are shown, Figure 7. In addition, the presence of $\mathrm{C}$ and $\mathrm{O}$ elements tends to be the most prominent in the EDX continuum since they are the critical components of the architectures of natural fibers [40].

The EDX study of both untreated and handled IVFs in terms of atomic percentage and weight is provided in Table II. It has been found that untreated IVF comprises almost 97.56 percent carbon weight, however, the carbon proportion is decreased to 97.32 percent and 75.08 percent for alkaline and potassium permanganate treatments, respectively, since chemical treatments could have eliminated the outer layer of the treated fiber [42]. This would be due to the IVF's more non-cellulosic components.

\subsection{Thermogravimetric analysis}

The thermal properties of untreated and treated IVF fibers are analyzed using TGA. Figure 8 demonstrate the TGA and DTG curves of these lignocellulosic fibers, an essential feature in biocomposite based on these fibers [30]. The first stage of decomposition was similar to untreated raw and chemically treated (IV) fibers, indicating the weight loss process. At the range between $30^{\circ} \mathrm{C}$ and $125^{\circ} \mathrm{C}$, a small weight loss $(6.15 \%)$ was demonstrated, which is agreed by several authors $[43,44]$.

It was shown that the first curve trend in DTG curves were decline in DTG curves, Figure 8 (b), it is proven that the water evaporation after $3 \%$ alkaline, $3 \%$ permanganate treatment. The same observation was found in Figure 8 (a). This is due to the reduction of the cellulose fiber's hydrophilic nature when the chemical treatment was employed on the IV fiber as the acquired for fiber reinforced polymer composites. Thus, the reduction moisture loss percentage in the both treated fibers could be the higher of crystallinity properties of the IV fiber [14]. When the temperature rises up to ${ }^{\circ} \mathrm{C}$, no significant peak is observed in the DTG curve and the similar was agreement with others work [45]. Beyond this temperature, thermal stability is decreasing and the fiber decomposition is happened, Figure 8 (a).

The second stage decomposition at $190^{\circ} \mathrm{C}$ until $290^{\circ} \mathrm{C}$ corresponds to hemicellulose decomposition and the third decomposition at $290^{\circ} \mathrm{C}-400^{\circ} \mathrm{C}$ correspond to cellulose and lignin decomposition. It was reported by another study [46] the least thermally stable was hemicellulose, the intermediate was cellulose and the lignin was the most resistant.

The untreated IV fibers started to degrade at around $200^{\circ} \mathrm{C}$ as shown in the degradation profile. The first degradation peat at $285^{\circ} \mathrm{C}$ correspond to the depolymerization of hemicellulose, pectin and glycosidic linkages of cellulose by $18.71 \%$ of weight loss. The $3 \%$ alkaline and $3 \%$ permanganate treated IVs. the peak was not visible, proving the complete removal of hemicellulose from the fiber. The major second 
peak was observed at $365.51^{\circ} \mathrm{C}$ due to degradation a-cellulose by $80.87 \%$ weight loss for untreated raw fiber [47], whereas $3 \%$ alkaline treatment and $3 \%$ permanganate -treated at $363^{\circ} \mathrm{C}$ and 350 with $67.7 \%$ and $62 \%$ weight loss respectively [48]. It can be noted that surface modification by both treatments reduced the thermal stability properties of the IV fibers, our findings are consistent with previous works $[49,50]$. From ambient to higher temperatures at $600^{\circ} \mathrm{C}$, the lignin degradation whose structure is a complex composition of aromatic rings with different branches may occur at a very low weight loss [51].

\subsection{Fourier transforms infrared spectroscopy (FTIR)}

The comparison of FTIR spectra of untreated raw fiber and chemically treated with $3 \%$ alkaline and $3 \%$ permanganate of Inula Viscosa (IV) fibers presented in Figure 9, shows absorption bands of chemical groups characteristic of lignocellulosic fiber compounds. The main characteristics of the spectrum of the untreated IVs at the peaks 3329, 2919, 2851, 1731, 1638, 1592, 1423, 1325, 1239, and $1028 \mathrm{~cm}^{-1}$ are acellulose, hemicelluloses, lignin, pectin, and water molecules contents. From the large absorption band observed around $3329 \mathrm{~cm}^{-1}$ is linked to $\mathrm{OH}$ and $\mathrm{CH}$ stretching of cellulose [52] . The strong adsorption peaks depicted at $2919 \mathrm{~cm}^{-1}$ and $2851 \mathrm{~cm}^{-1}$ are related to $\mathrm{C}-\mathrm{H}$ stretching vibrations from $\mathrm{CH}$ and $\mathrm{CH} 2$ in cellulose and hemicellulose, respectively [53]. An observable peak around $1731 \mathrm{~cm}^{-1}$ corresponds to the $\mathrm{C}=\mathrm{O}$ stretching of hemicelluloses $[21,54]$. The band around $1638 \mathrm{~cm}^{-1}$ was related to the $\mathrm{O}-\mathrm{H}$ bending of water absorbed into cellulose fiber structure The peak around $1592 \mathrm{~cm}^{-1}$ corresponds to the aromatic ring $\mathrm{C}=\mathrm{C}$ of the phenyl propane group in lignin [55]. Also, a small peak near $1423 \mathrm{~cm}^{-1}$ belongs to the aromatic skeletal vibrations and ring breathing with $\mathrm{C}-0$ stretching in lignin [56]. The peak observed at $1325 \mathrm{~cm}^{-1}$ is attributed to $\mathrm{C}-\mathrm{H}$ and $\mathrm{C}-\mathrm{O}$ groups' bending vibration of the aromatic ring in polysaccharides[57]. Additionally, A small peak around $1239 \mathrm{~cm}^{-1}$ belongs to the acetyl group's $\mathrm{C}-0$ stretching in hemicelluloses [54]. A visible peak at $1028 \mathrm{~cm}^{-1}$ is related to the stretching of $\mathrm{C}-0$ groups of cellulose [43]. The fibers' FTIR spectra confirm the compositional changes in permanganate and alkali-treated fibers, Figure 9. The two peaks at $1239 \mathrm{~cm}^{-1}$ and $1731 \mathrm{~cm}^{-1}$ were observed in FTIR of untreated fibers, which correspond to hemicelluloses, disappeared in the spectrum of the permanganate and alkali-treated fibers. This result could be explained by the elimination of the residual hemicellulosic materials after the treatment. The removal of an important amount of lignin by the chemical treatment can be noticed through the disappearance of the peaks located at about $1325 \mathrm{~cm}^{-1}$ and $1423 \mathrm{~cm}^{-1}$. It is to demonstrate that the removal of hemicelluloses and lignin from the treated (IV) supports the results of the chemical analysis.

\subsection{XRD analysis}

Figure 10 illustrates the XRD pattern of the $3 \%$ alkaline, $3 \%$ permanganate treated and raw fibers specimen of IV and the corresponding planes involved. From the Figure 10, it was shown that each specimen showed two peaks, respectively. For $3 \%$ permanganate and $3 \%$ alkaline treatment, the first peak represents the amorphous peak demonstrated at $2 \theta=15.96^{\circ}, 16.45^{\circ}$ and $16.06^{\circ}$ at lattice plane (110). respectively. While for the second-high intensity peak the $3 \%$ alkaline , $3 \%$ permanganate and 
untreated IV fibers represents the crystalline peak observed at $2 \theta=22.48^{\circ}, 22.52^{\circ}$ and $22.08^{\circ}$ respectively, belongs to the (200) plane of cellulose [40]. The value of crystallinity index (Cl) was higher for $3 \%$ permanganate at $55.93 \%$ followed by $3 \%$ alkaline treatment at $54.25 \%$ and untreated raw fiber at $51.63 \%$. It was shown that chemically treated with alkaline and treatment were improved compared to untreated.

The increase in $\mathrm{Cl}$ with permanganate and alkali treatments is related to the loosening of cellulosic chains resulting in the disappearance of excess amorphous constituents, such as lignin, hemicellulose, etc. [58].This result was agreed with SEM morphology the impurities of fiber was removed with chemical treatment.. Furthermore, the crystallite size (CS) of the untreated raw, the $3 \%$ alkaline and the $3 \%$ permanganate-treated of the IVFs were obtained as $0.8 \mathrm{~nm}, 1.85 \mathrm{~nm}$ and $2.0 \mathrm{~nm}$, respectively. The crystallite size may reduce the chemical activity and the water absorption capacity of the fibers.

\subsection{Tensile test}

The study of mechanical properties of natural fiber reinforced polymer composites is important to understand their potential for various structural applications. Figure 11 (a), depicts the impact of untreated raw, $3 \% \mathrm{NaOH}$ and $3 \%$ permanganate-treated IVFs on the tensile strength of IVFs. From the graph, the tensile strength trend was increasing for $3 \%$ permanganate, followed by $3 \%$ alkaline treatment compared to untreated raw fiber with the value of 195.88MPa, 173.047 MPa and 163.60 MPa, respectively. The increased tensile strength of chemically treated IV fibers due to the elimination of impurities from the IV fiber surface. Previous research shows the values of tensile strength from plants fiber was approximate with IVs fiber such as sisal (274-526 MPa) [59], date palm (170-275 MPa) [60], Lygeum Spartum (LS) (113 MPa) [43], pineapple leaf fiber (PALF), and Arundo Donax $248 \mathrm{MPa}$ [30]. The strain rate of untreated fibers and alkali and permanganate treated IVFs is $1.172 \%, 1.439 \%$, and $1.562 \%$ respectively, which directly affects the micro fibrillation angle of the IVFs Figure 11 (b). The Young modulus of raw natural fibers and fibers treated with alkali and permanganate is $11.407 \mathrm{GPa}, 11.596$ $\mathrm{GPa}$, and $12.25 \mathrm{GPa}$, respectively, Figure 11 (c). The tensile modulus of IV fibers with $3 \%$ alkaline and 3\% permanganate was higher than untreated raw fiber. The values are quite approaching to other plant fiber such as artichoke (11.6 GPa), sisal (9.4 - 22 GPa) and bamboo (11-17 GPa) [30].

\subsection{Droplet test}

This work evaluated the bonding strength between the IV fiber and epoxy resin by a droplet test. As shown in Figure 12, the IFFS interfacial shear strength was obtained from the test results. Unlike other fiber pull-offs, this technique allows the average shear stress to be calculated once the fiber is peeled off by force $\left(F_{d}\right)$.

It should be noted that the apparent adhesive force measured with micro bonding tests varies greatly. The variability causes this in the IV fiber dimension that have different diameters. The mechanism of droplet test showed that when the increase of load to pull out the IV fiber, the easily IVs fiber to break. From this result, the higher interfacial shear strength was permanganate-treated fiber with $4.50 \mathrm{MPa}$, followed by alkaline treatment, and untreated of IVs fiber with $3.36 \mathrm{MPa}$ and $2.93 \mathrm{MPa}$, respectively. The 
increased value of $t$ IFFS for permanganate was $53.58 \%$ and alkaline treatment by $11,26 \%$ compared to untreated IVs fiber. The data obtained is comparable to the IFFS of flax, hemp, and sisal [61]. The adhesion between the epoxy resin and the Inula Viscosa fiber was improved by permanganate treatment and alkalization. According to the results, the adhesion between the treated Inula Viscosa fiber/epoxy was better than the adhesion bonding between the untreated Inula Viscosa fiber/epoxy.

\section{Conclusions}

In this study, the untreated IVs, 3\% alkaline treated IVs, and $3 \%$ permanganate treated IVs were evaluated for their physical, morphological, crystalline structure, thermal degradation, mechanical and micromechanical properties. The conclusions concluded from the experiments.

1. The density of untreated raw IVF and alkali and permanganate treatment IVF is lower than that other natural fibers have.

2. The decrease in diameter for alkaline, permanganate-treated fiber for IVs fiber due to impurities surface removal compared to untreated raw IVs fiber.

3. The XRD analysis confirms that the treated IVFs was higher strength and more resistant to humidity than untreated raw ones obtained from $\mathrm{Cl}$ and $\mathrm{CS}$ values.

4. The reduce hemicellulose, lignin, and wax content of IVs fiber by chemical treatment was confirmed by FTIR and were agreed with surface morphology in SEM analysis.,.

5. The thermal stability of untreated and chemically treated with alkaline and permanganate of IV fiber can be withstanding up to $190^{\circ} \mathrm{C}$.

The tensile properties of IVs fiber such as tensile strength, Young's modulus, and strain to break depicted the improved strength by chemically treated IVFs due to the higher cellulose content and $\mathrm{Cl}$ values. The highest IFSS properties were permanganate, followed by alkaline treatment and untreated raw fiber.

This finding showed that the importance of chemical fiber treatment leads to the natural fiber reinforced polymer composites' enhanced properties. Overall, the chemical modification of IVs fiber exhibited better mechanical properties than untreated. The is due to that the improved adhesion and polar interaction between the fiber and polymer interfaces.

\section{Declarations}

\section{Acknowledgements}

We would like to extend our deepest gratitude to Biocomposite Technology Laboratory, INTROP, Universiti Putra Malaysia, for supporting this work and doing all experimental.

\section{References}


1. Siva, R., et al., Study on a Novel natural cellulosic fiber from Kigelia africana fruit: Characterization and analysis. Carbohydrate Polymers, 2020: p. 116494.

2. Dhakal, H.N., et al., Effect of basalt fibre hybridisation on post-impact mechanical behaviour of hemp fibre reinforced composites. Composites Part A: Applied Science and Manufacturing, 2015. 75: p. 5467.

3. Vinod, A., S. Siengchin, and J. Parameswaranpillai, Renewable and sustainable biobased materials: An assessment on biofibers, biofilms, biopolymers and biocomposites. Journal of Cleaner Production, 2020: p. 120978.

4. Gheith, M.H., et al., Flexural, thermal and dynamic mechanical properties of date palm fibres reinforced epoxy composites. Journal of Materials Research and Technology, 2019. 8(1): p. 853-860.

5. Jawaid, M., M.S. Salit, and O.Y. Alothman, Green biocomposites: design and applications. 2017: Springer.

6. Müssig, J. and N. Graupner, Test Methods for Fibre/Matrix Adhesion in Cellulose Fibre-Reinforced Thermoplastic Composite Materials: A Critical Review. Reviews of Adhesion and Adhesives, 2020. 8(2): p. 68-129.

7. Asim, M., et al., Thermal, physical properties and flammability of silane treated kenaf/pineapple leaf fibres phenolic hybrid composites. Composite Structures, 2018. 202: p. 1330-1338.

8. Sathishkumar, T., et al., Mechanical properties and water absorption of short snake grass fiber reinforced isophthallic polyester composites. Fibers and Polymers, 2014. 15(9): p. 1927-1934.

9. Jawaid, M. and H.A. Khalil, Cellulosic/synthetic fibre reinforced polymer hybrid composites: A review. Carbohydrate polymers, 2011. 86(1): p. 1-18.

10. Baskaran, P., et al., Characterization of new natural cellulosic fiber from the bark of dichrostachys cinerea. Journal of Natural Fibers, 2018. 15(1): p. 62-68.

11. Sanjay, M., et al., Characterization and properties of natural fiber polymer composites: $A$ comprehensive review. Journal of Cleaner Production, 2018. 172: p. 566-581.

12. Senthamaraikannan, P., et al., Physico-chemical and thermal properties of untreated and treated Acacia planifrons bark fibers for composite reinforcement. Materials Letters, 2019. 240: p. 221-224.

13. Bledzki, A. and J. Gassan, Composites reinforced with cellulose based fibres. Progress in polymer science, 1999. 24(2): p. 221-274.

14. Izani, M.N., et al., Effects of fiber treatment on morphology, tensile and thermogravimetric analysis of oil palm empty fruit bunches fibers. Composites Part B: Engineering, 2013. 45(1): p. 1251-1257.

15. Asim, M., et al., The effect of silane treated fibre loading on mechanical properties of pineapple leaf/kenaf fibre filler phenolic composites. Journal of Polymers and the Environment, 2018. 26(4): $p$. 1520-1527.

16. Arsyad, M. and R. Soenoko. The effects of sodium hydroxide and potassium permanganate treatment on roughness of coconut fiber surface. in MATEC Web of Conferences. 2018. EDP Sciences. 
17. Rajeshkumar, G., Effect of sodium hydroxide treatment on dry sliding wear behavior of Phoenix sp. fiber reinforced polymer composites. Journal of Industrial Textiles, 2020: p. 1528083720918948.

18. Manimaran, P., et al., Physicochemical properties of new cellulosic fibers from Azadirachta indica plant. Journal of Natural Fibers, 2018. 15(1): p. 29-38.

19. Amutha, V. and B. Senthilkumar, Physical, Chemical, Thermal, and Surface Morphological Properties of the Bark Fiber Extracted from Acacia Concinna Plant. Journal of Natural Fibers, 2019: p. 1-14.

20. Kumar, R., et al., Characterization of New Cellulosic Fiber from the Bark of Acacia nilotica L. Plant. Journal of Natural Fibers, 2020: p. 1-10.

21. Jayaramudu, J., B. Guduri, and A.V. Rajulu, Characterization of new natural cellulosic fabric Grewia tilifolia. Carbohydrate polymers, 2010. 79(4): p. 847-851.

22. Kumar, R., et al., Physicochemical and thermal properties of ceiba pentandra bark fiber. Journal of Natural Fibers, 2018. 15(6): p. 822-829.

23. Ganán, P., et al., Biological natural retting for determining the hierarchical structuration of banana fibers. Macromolecular Bioscience, 2004. 4(10): p. 978-983.

24. Shaker, K., et al., Extraction and characterization of novel fibers from Vernonia elaeagnifolia as a potential textile fiber. Industrial Crops and Products, 2020. 152: p. 112518.

25. Imoisili, P.E. and T.-C. Jen, Mechanical and water absorption behaviour of potassium permanganate (KMnO4) treated plantain (Musa Paradisiaca) fibre/epoxy bio-composites. Journal of Materials Research and Technology, 2020. 9(4): p. 8705-8713.

26. Vijay, R., et al., Characterization of silane-treated and untreated natural fibers from stem of leucas aspera. Journal of Natural Fibers, 2020: p. 1-17.

27. Elenga, R., et al., On the microstructure and physical properties of untreated raffia textilis fiber. Composites Part A: Applied Science and Manufacturing, 2009. 40(4): p. 418-422.

28. Rao, K.M.M. and K.M. Rao, Extraction and tensile properties of natural fibers: Vakka, date and bamboo. Composite structures, 2007. 77(3): p. 288-295.

29. Truong, M., et al., A comparative study on natural fibre density measurement. The Journal of The Textile Institute, 2009. 100(6): p. 525-529.

30. Fiore, V., T. Scalici, and A. Valenza, Characterization of a new natural fiber from Arundo donax L. as potential reinforcement of polymer composites. Carbohydrate polymers, 2014. 106: p. 77-83.

31. Kabir, M., et al., Tensile properties of chemically treated hemp fibres as reinforcement for composites. Composites Part B: Engineering, 2013. 53: p. 362-368.

32. Miller, B., P. Muri, and L. Rebenfeld, A microbond method for determination of the shear strength of a fiber/resin interface. Composites Science and Technology, 1987. 28(1): p. 17-32.

33. Varma, I., S.A. Krishnan, and S. Krishnamoorthy, Effect of chemical treatment on density and crystallinity of jute fibers. Textile Research Journal, 1989. 59(6): p. 368-370.

34. Ouarhim, W., et al., A Comparison between Sabra and Alfa Fibers in Rubber Biocomposites. Journal of Bionic Engineering, 2019. 16(4): p. 754-767. 
35. Madhu, P., et al., A new study on effect of various chemical treatments on Agave Americana fiber for composite reinforcement: Physico-chemical, thermal, mechanical and morphological properties. Polymer Testing, 2020. 85: p. 106437.

36. Mukhopadhyay, U. and A. Mukherjee, Density and X-Ray Diffraction Studies of Jute at Different Stages of Growth. Textile Research Journal, 1977. 47(3): p. 224-227.

37. Musa, A. and S. Duna, Effect of Metakaolin on the Strength Properties of Sisal Fibre Reinforced Concrete. Current Journal of Applied Science and Technology, 2017: p. 1-12.

38. Mouli, K.C., et al., Strength studies on banana fibre concrete with metakaolin. International Journal of Civil Engineering and Technology, 2019. 10: p. 684-689.

39. Moshi, A.A.M., et al. Characterization of New Natural Cellulosic Fibers-A Comprehensive Review. in IOP Conference Series: Materials Science and Engineering. 2019. IOP Publishing.

40. Manimaran, P., et al., Study on characterization of Furcraea foetida new natural fiber as composite reinforcement for lightweight applications. Carbohydrate Polymers, 2018. 181: p. 650-658.

41. Borchani, K.E., C. Carrot, and M. Jaziri, Untreated and alkali treated fibers from Alfa stem: effect of alkali treatment on structural, morphological and thermal features. Cellulose, 2015. 22(3): p. 15771589.

42. Amroune, S., et al., Investigation of the date palm fiber for green composites reinforcement: thermophysical and mechanical properties of the fiber. Journal of Natural Fibers, 2019: p. 1-18.

43. Belouadah, Z., A. Ati, and M. Rokbi, Characterization of new natural cellulosic fiber from Lygeum spartum L. Carbohydrate Polymers, 2015. 134: p. 429-437.

44. Mazlan, A., et al. Thermal properties of pineapple leaf/kenaf fibre reinforced vinyl ester hybrid composites. in IOP Conference Series: Materials Science and Engineering. 2019. IOP Publishing.

45. De Rosa, I.M., et al., Morphological, thermal and mechanical characterization of okra (Abelmoschus esculentus) fibres as potential reinforcement in polymer composites. Composites Science and Technology, 2010. 70(1): p. 116-122.

46. Asim, M., et al., Thermo-Gravimetric Analysis of Various Ratio of Blended Phenolic and Epoxy Composites. IJITEE, 2019. 9: p. 5435-5439.

47. Rebelo, V., et al., Effects of mercerization in the chemical and morphological properties of amazon piassava. Polímeros, 2019. 29(1).

48. Shanmugasundaram, N., I. Rajendran, and T. Ramkumar, Characterization of untreated and alkali treated new cellulosic fiber from an Areca palm leaf stalk as potential reinforcement in polymer composites. Carbohydrate Polymers, 2018. 195: p. 566-575.

49. Siakeng, R., et al., Effects of surface treatments on tensile, thermal and fibre-matrix bond strength of coir and pineapple leaf fibres with poly lactic acid. Journal of Bionic Engineering, 2018. 15(6): p. 1035-1046.

50. Kabir, M., et al., Effects of chemical treatments on hemp fibre structure. Applied Surface Science, 2013. 276: p. 13-23. 
51. Khan, A., et al., Characterization of natural fibers from cortaderia selloana grass (pampas) as reinforcement material for the production of the composites. Journal of Natural Fibers, 2020: p. 1-9.

52. Popescu, C.-M., et al., Spectroscopic study of acetylated kraft pulp fibers. Carbohydrate polymers, 2012. 88(2): p. 530-536.

53. Maache, M., et al., Characterization of a novel natural cellulosic fiber from Juncus effusus $L$. Carbohydrate polymers, 2017. 171: p. 163-172.

54. Senthamaraikannan, P. and M. Kathiresan, Characterization of raw and alkali treated new natural cellulosic fiber from Coccinia grandis. L. Carbohydrate Polymers, 2018. 186: p. 332-343.

55. Xia, L., et al., Morphologies and properties of Juncus effusus fiber after alkali treatment. Cellulose, 2020. 27(4): p. 1909-1920.

56. Zhang, H., et al., Influence of alkali treatment on flax fiber for use as reinforcements in polylactide stereocomplex composites. Polymer Engineering \& Science, 2015. 55(11): p. 2553-2558.

57. Liu, Y., et al., Characterization of silane treated and untreated natural cellulosic fibre from corn stalk waste as potential reinforcement in polymer composites. Carbohydrate polymers, 2019. 218: p. 179187.

58. Vijay, R., et al., Characterization of raw and alkali treated new natural cellulosic fibers from Tridax procumbens. International journal of biological macromolecules, 2019. 125: p. 99-108.

59. de Andrade Silva, F., N. Chawla, and R.D. de Toledo Filho, Tensile behavior of high performance natural (sisal) fibers. Composites Science and Technology, 2008. 68(15-16): p. 3438-3443.

60. Al-Khanbashi, A., K. Al-Kaabi, and A. Hammami, Date palm fibers as polymeric matrix reinforcement: fiber characterization. Polymer composites, 2005. 26(4): p. 486-497.

61. Czigány, T., B. Morlin, and Z. Mezey, Interfacial adhesion in fully and partially biodegradable polymer composites examined with microdroplet test and acoustic emission. Composite Interfaces, 2007. 14(7-9): p. 869-878.

\section{Tables}

Table I. Abbreviations of samples names.

\begin{tabular}{|ll|}
\hline Names of samples & Abbreviations \\
\hline Raw Inula Viscosa fiber & R-IVF \\
Alkali treated Inula Viscosa fiber & A-IVF \\
Permanganate treated Inula Viscosa fiber & P-IVF \\
\hline
\end{tabular}

\section{Table II. (a) The elements composition found on the surface of R-IVF.}




\begin{tabular}{|ccccc|}
\hline R-IVF & & & & \\
\hline Element & Weight \% & Atom \% & Formula & Compnd \% \\
\hline $\boldsymbol{C}$ & 97.56 & 98.78 & $\mathrm{C}$ & 97.56 \\
\hline $\boldsymbol{C}$ & 0.98 & 0.75 & & - \\
\hline $\boldsymbol{S}$ & 0.36 & 0.14 & $\mathrm{SO}$ & 0.91 \\
$\mathrm{Ca}$ & 1.10 & 0.33 & $\mathrm{CaO}$ & 1.54 \\
\hline Total & 100.00 & 100.00 & & 100.00 \\
\hline
\end{tabular}

Table II. (b) The elements composition found on the surface of A-IVF

\begin{tabular}{|ccccc|}
\hline A- IVF & & & & \\
\hline Element & Weight \% & Atom \% & Formula & Compnd \% \\
\hline $\boldsymbol{C}$ & 97.32 & 98.84 & $\mathrm{C}$ & 97.32 \\
$\boldsymbol{O}$ & 0.76 & 0.58 & & - \\
$\mathrm{Ca}$ & 1.91 & 0.58 & $\mathrm{CaO}$ & 2.68 \\
\hline Total & 100.00 & 100.00 & & 100.00 \\
\hline
\end{tabular}

Table II. (c) The elements composition found on the surface of P-IVF

\begin{tabular}{|ccccc|}
\hline P- IVF & & & & \\
\hline Element & Weight \% & Atom \% & Formula & Compnd \% \\
\hline $\boldsymbol{C}$ & 75.08 & 91.39 & $\mathrm{C}$ & 75.08 \\
\hline $\boldsymbol{O}$ & 2.22 & 2.03 & & - \\
\hline $\mathbf{M g}$ & 0.60 & 0.36 & $\mathrm{MgO}$ & 1.00 \\
\hline $\boldsymbol{C a}$ & 3.44 & 1.26 & $\mathrm{CaO}$ & 4.82 \\
\hline $\mathbf{M n}$ & 17.61 & 4.69 & $\mathrm{Mn}$ & 17.61 \\
\hline $\boldsymbol{F e}$ & 1.04 & 0.27 & $\mathrm{Fe} 203$ & 1.49 \\
\hline Total & 100.00 & 100.00 & & 100.00 \\
\hline
\end{tabular}

Figures 


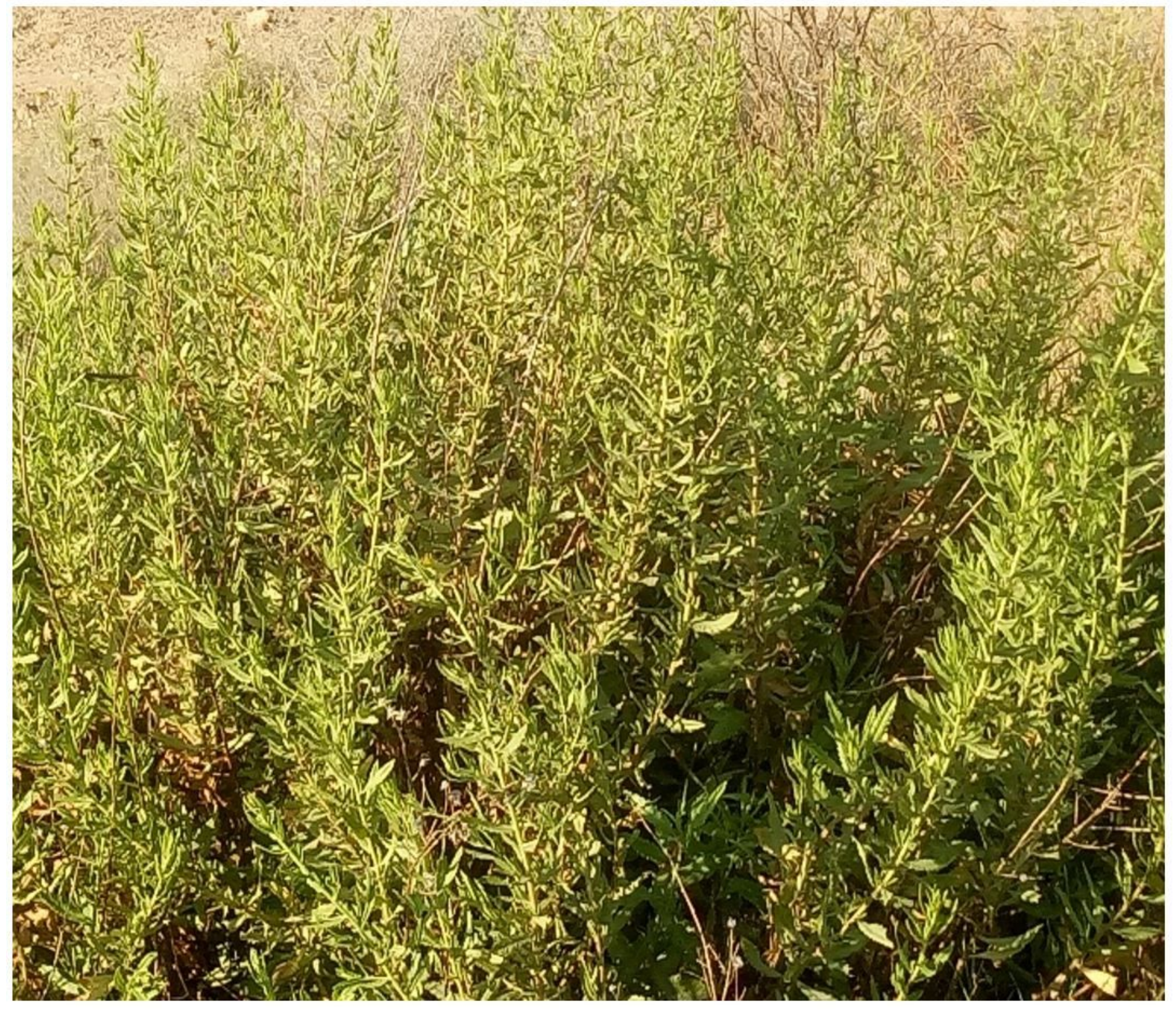

\section{Figure 1}

IV plant. 


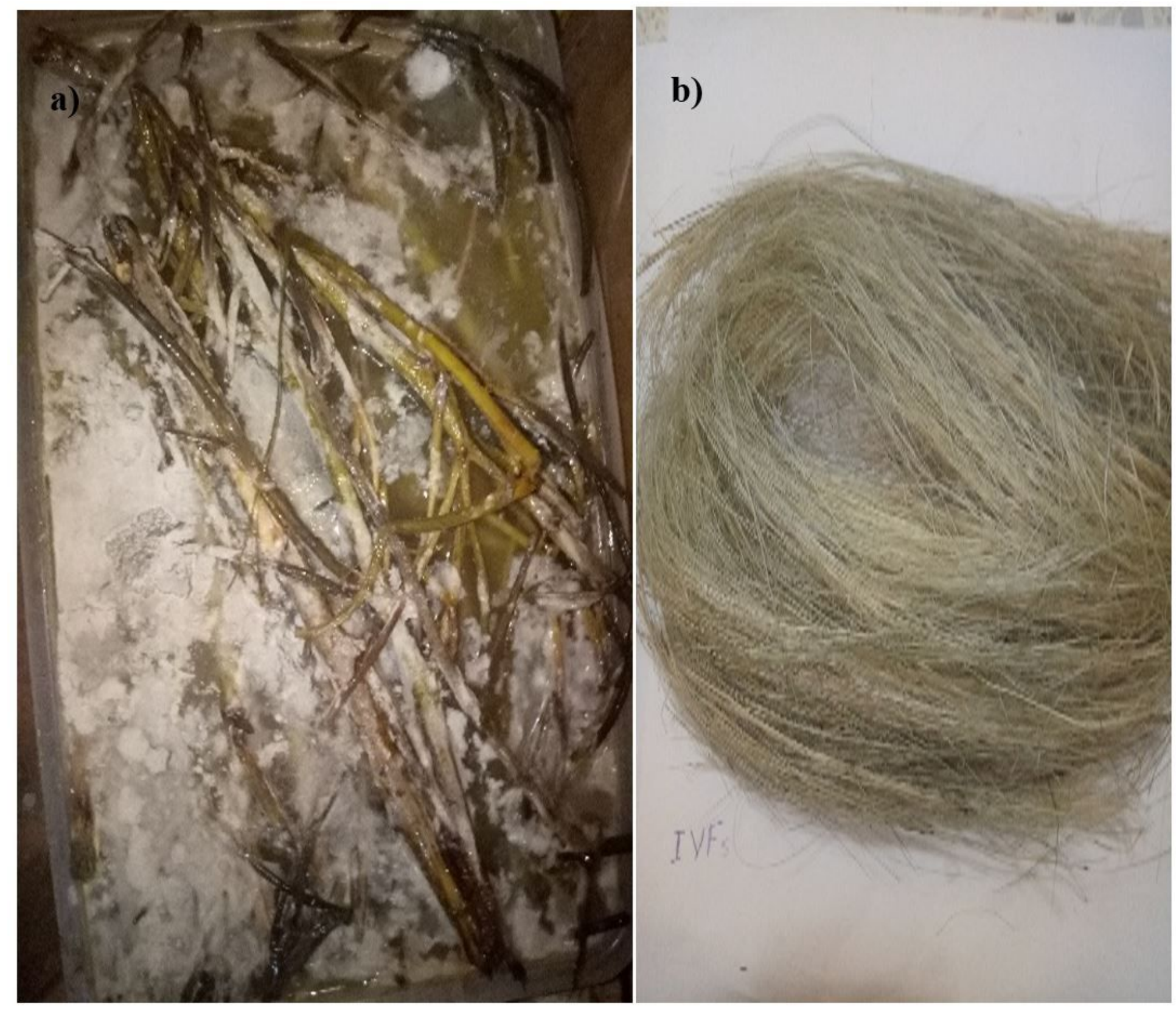

Figure 2

IV under the retting process(a), and extracted fibers (b). 


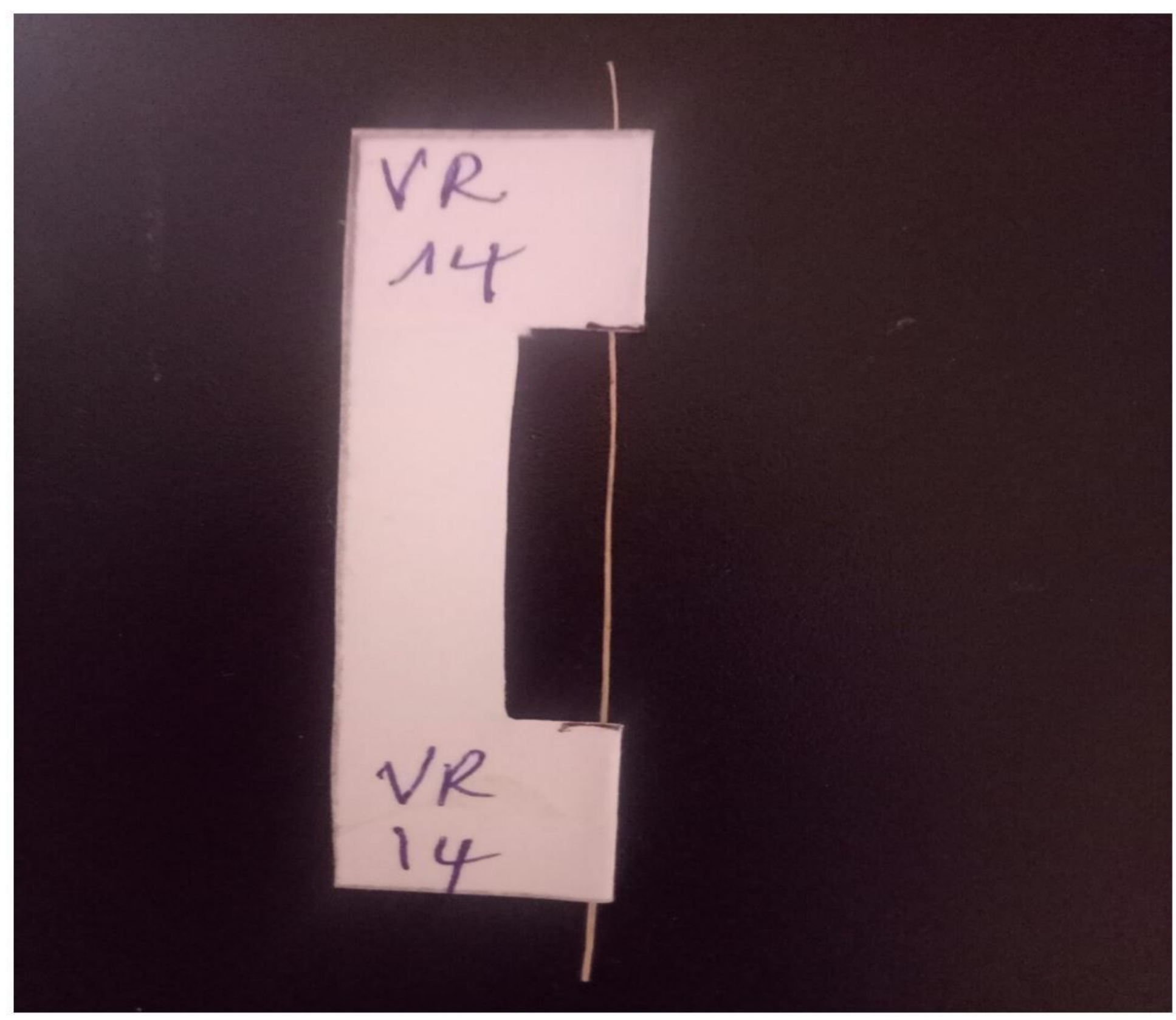

Figure 3

IV under the retting process(a), and extracted fibers (b). 

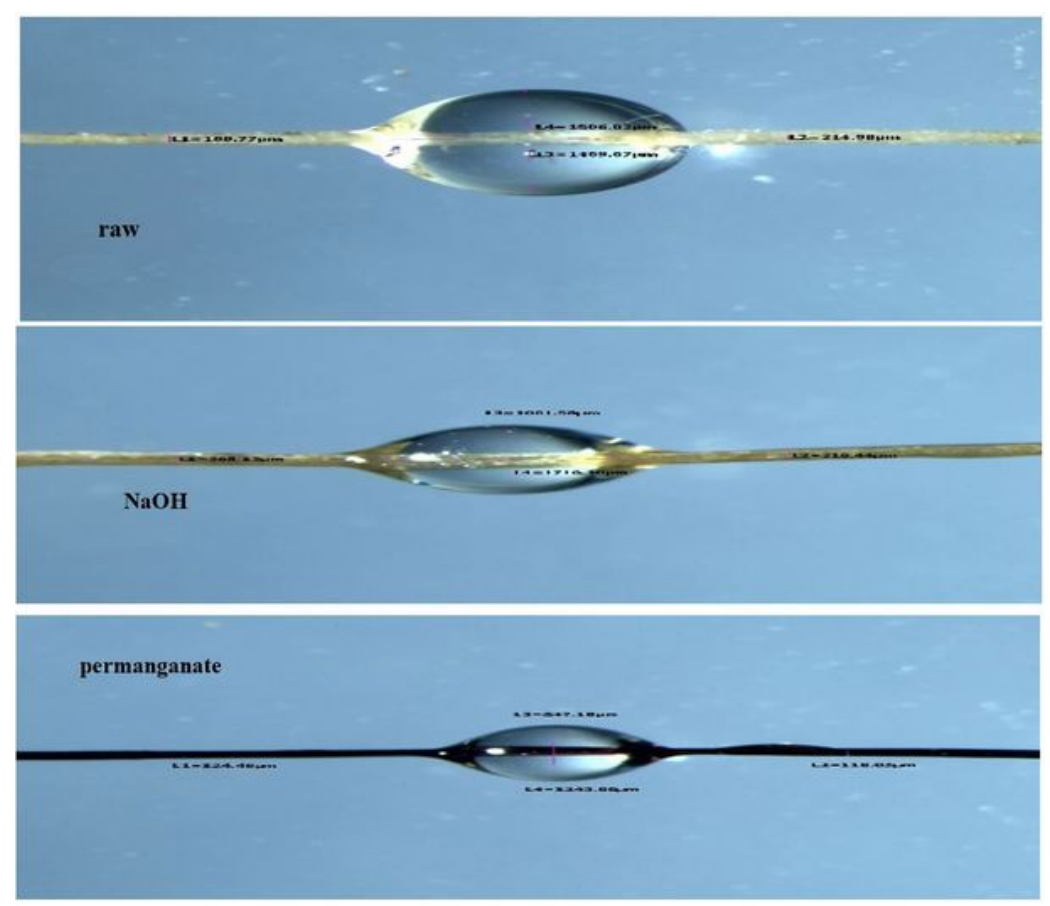

a
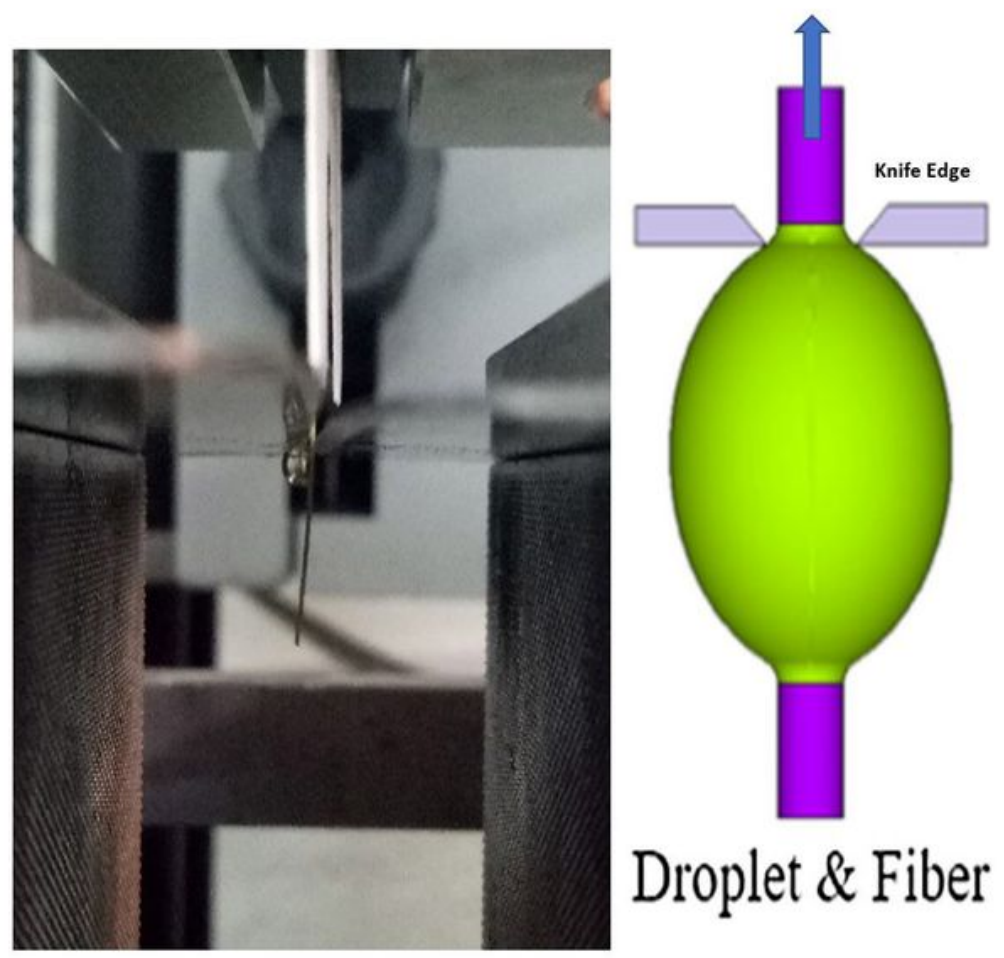

Droplet \& Fiber

b

Figure 4

Droplet sample of R-IVF, A-IVF, P-IVF (a), and Droplet test of IVF (b). 


\section{a)}

b)

\section{c)}

sis

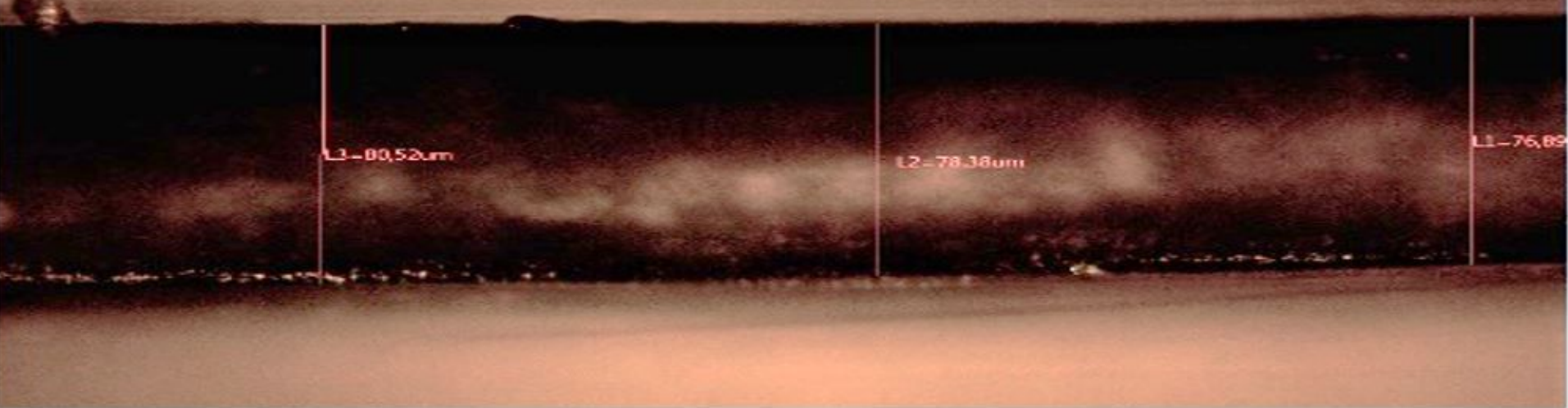

Figure 5

Optical microscope images of R-IVF (a), A-IVF (b), and P-IVF (c). 

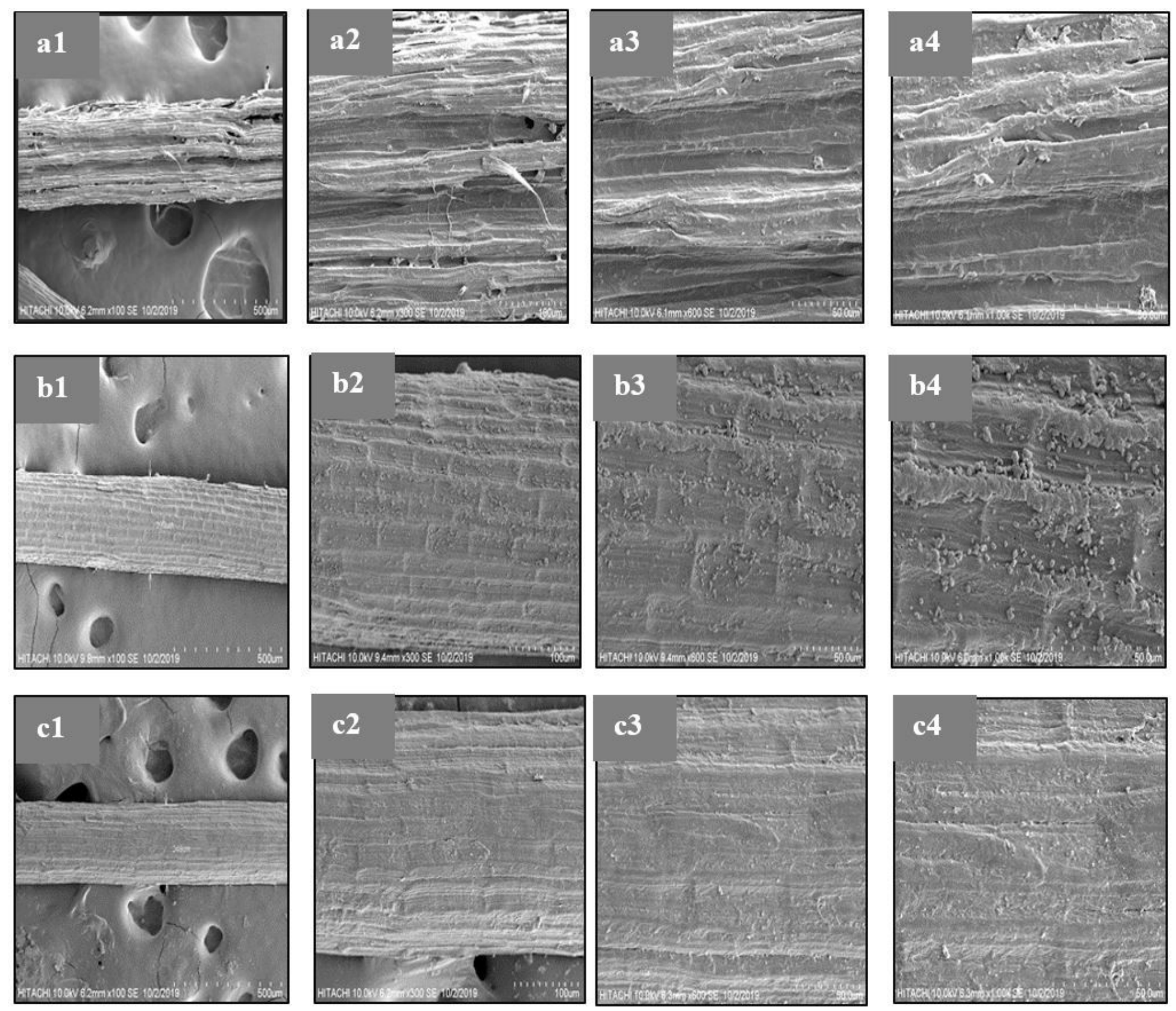

Figure 6

SEM of R-IVF (a), A-IVF (b), and P-IVF (c). 

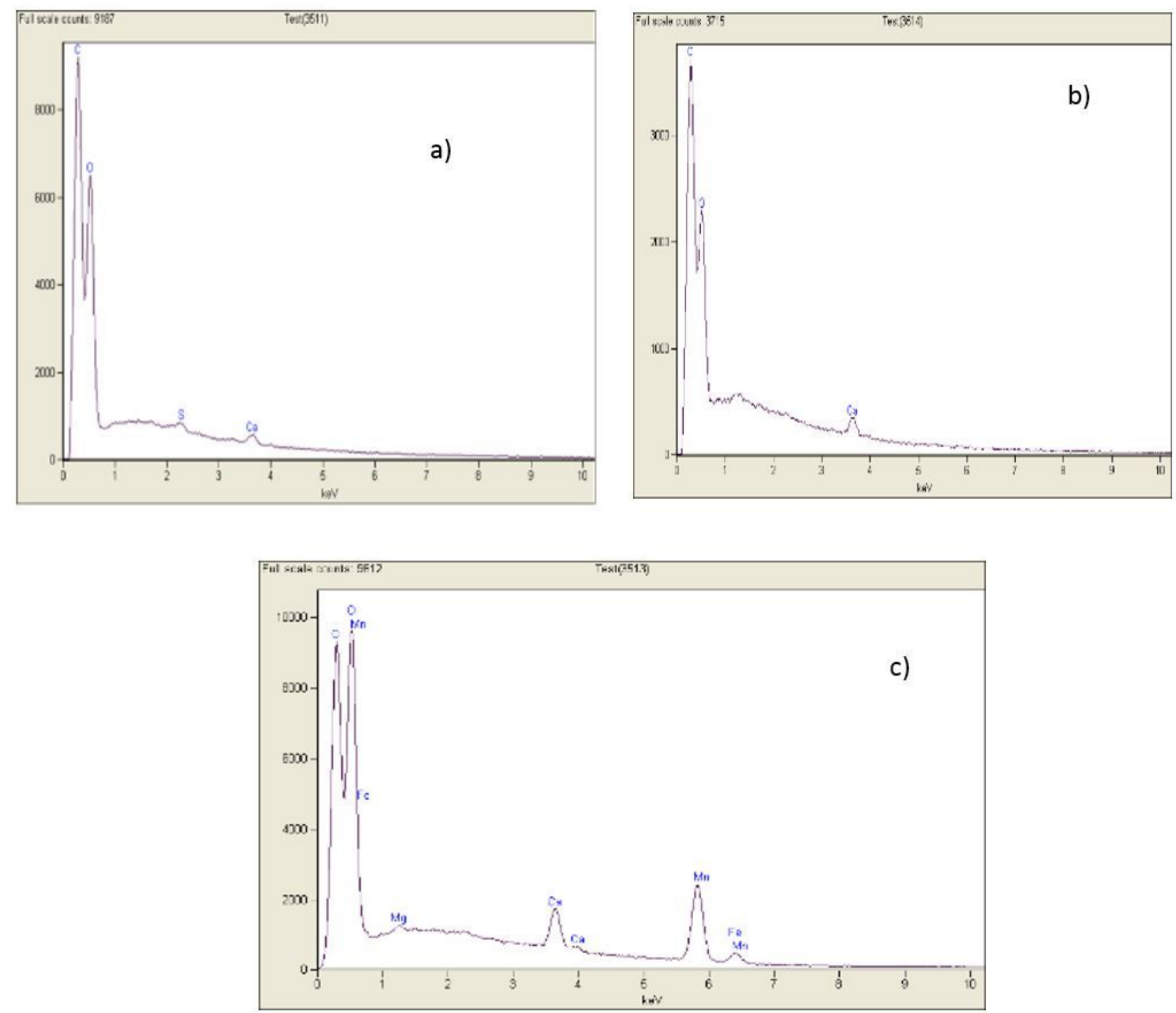

Figure 7

EDX analysis of R-IVF (a), A-IVF (b), and P-IVF (c) 

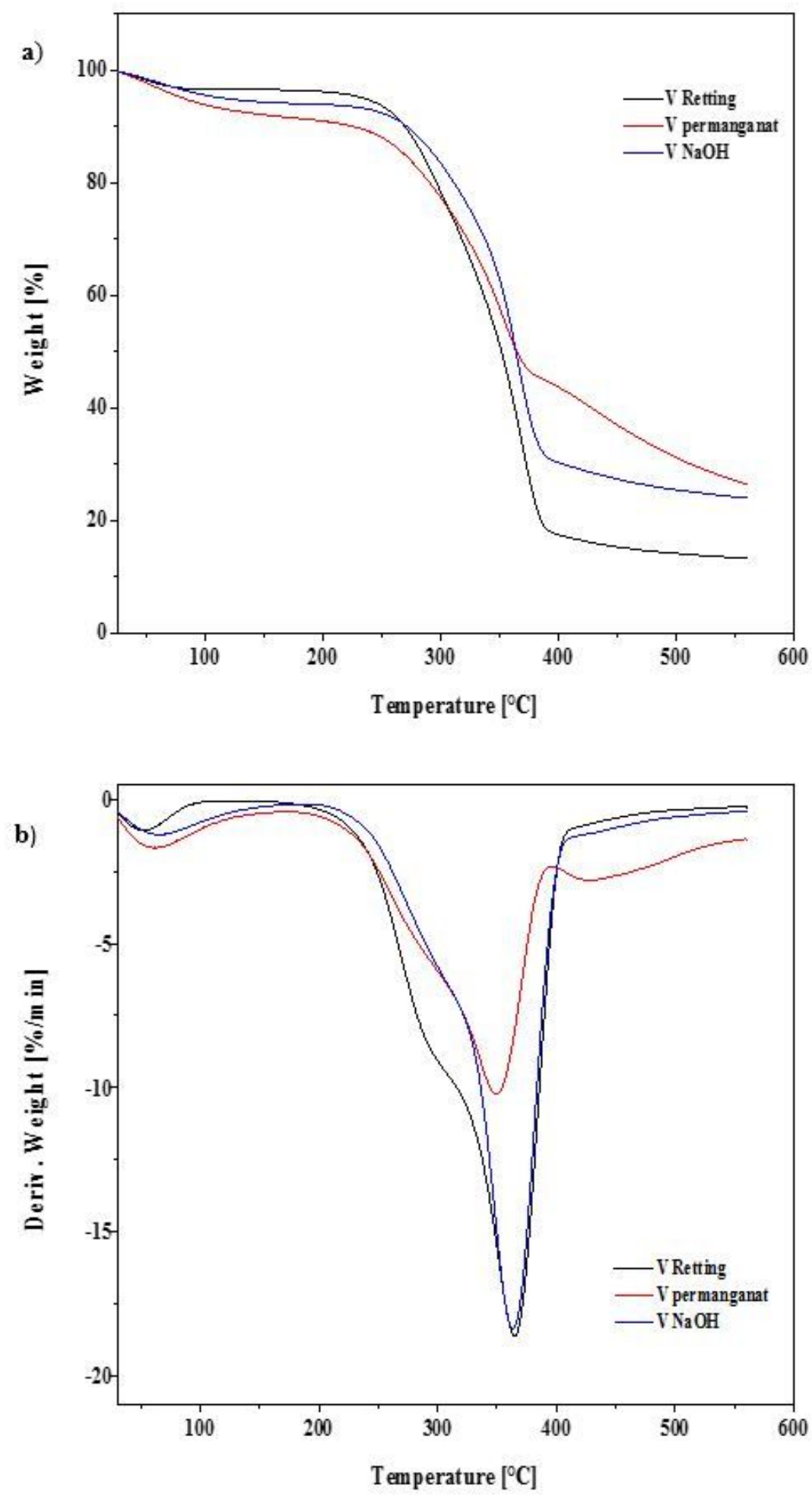

\section{Figure 8}

TGA (a) and DTG (b) curves of R-IVF, A-IVF and P-IVF. 


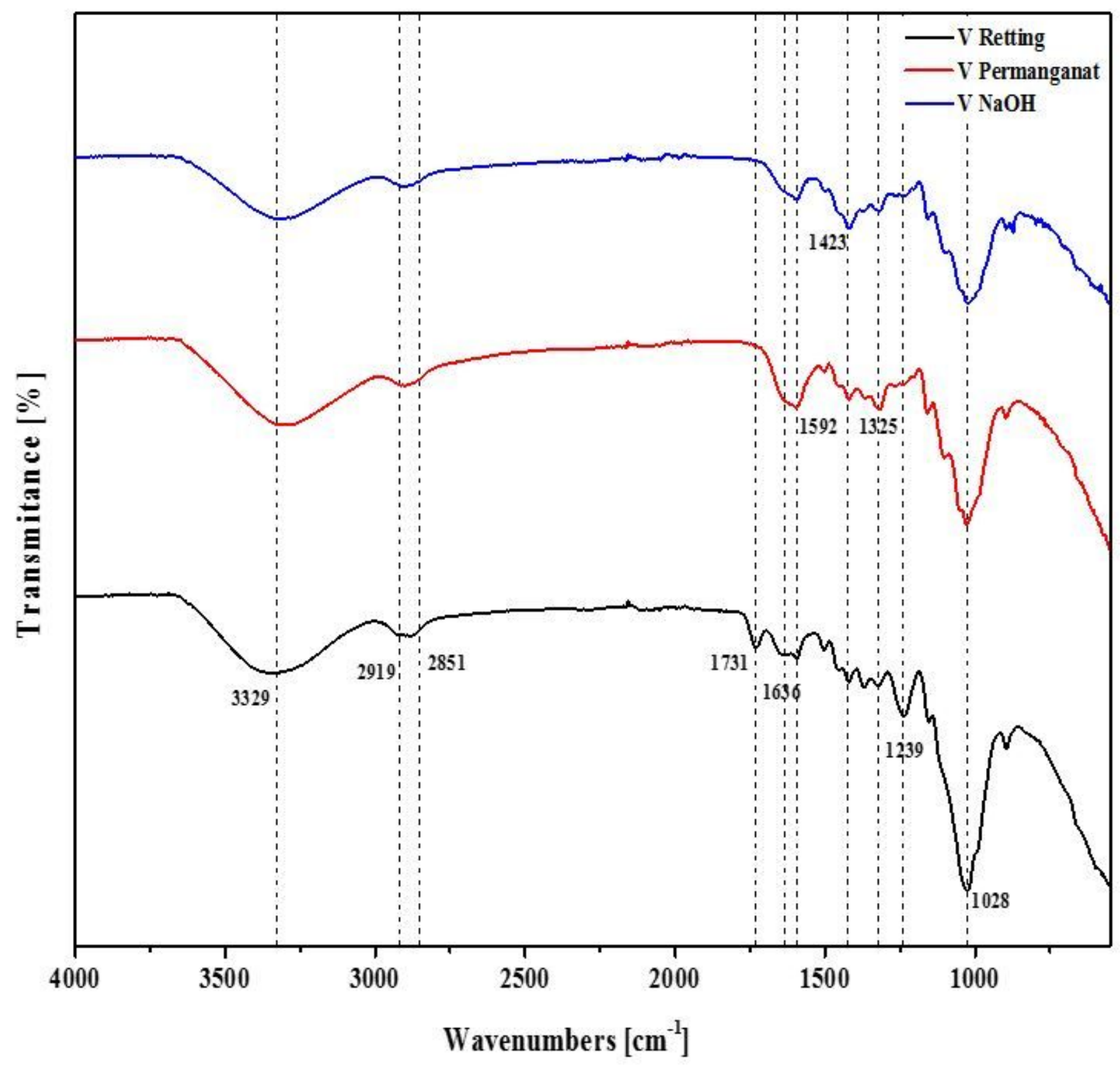

Figure 9

FTIR spectra of R-IVF, A-IVF, and P-IVF. 


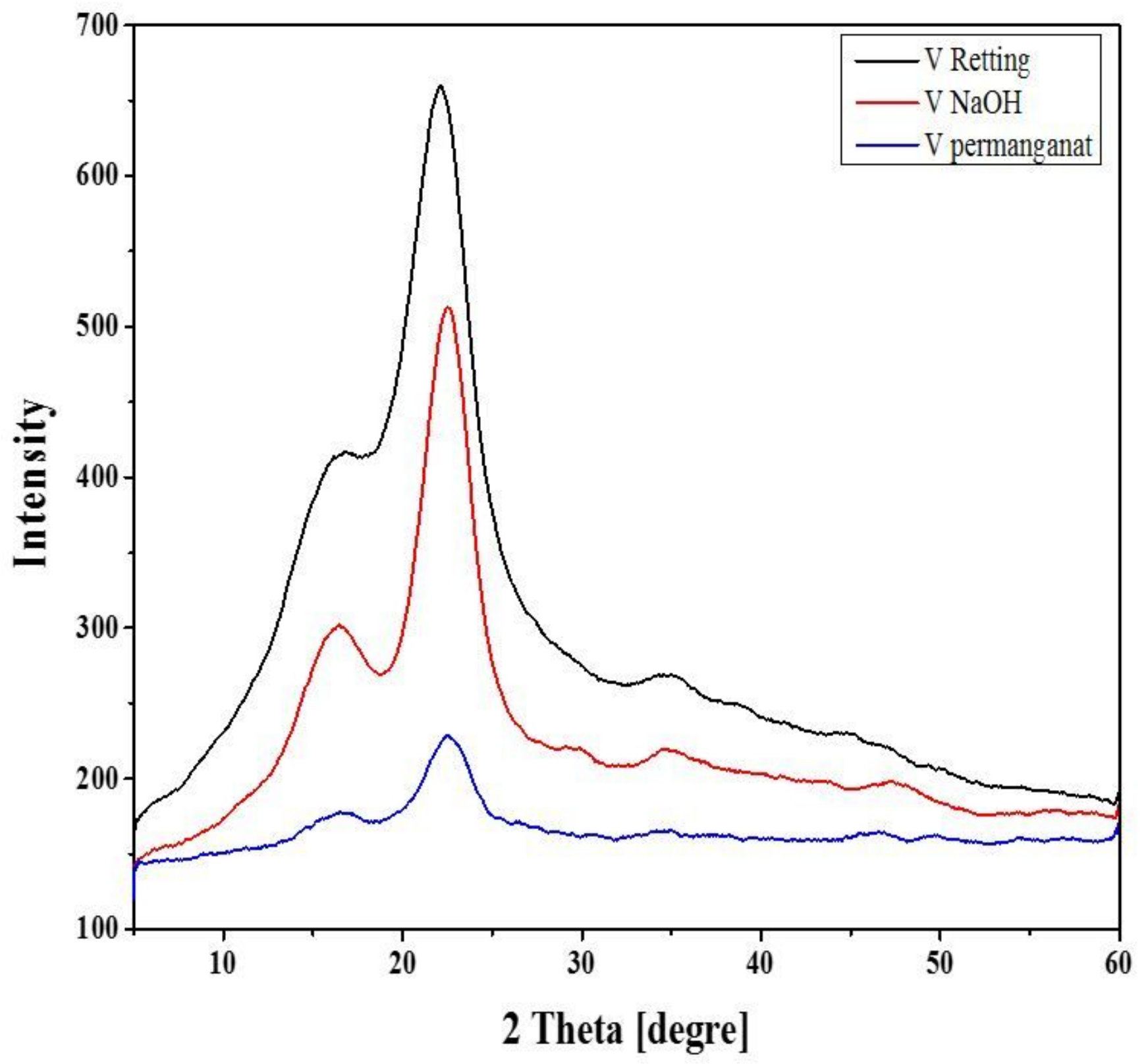

Figure 10

XRD pattern of R-IVF, A-IVF and P-IVF 

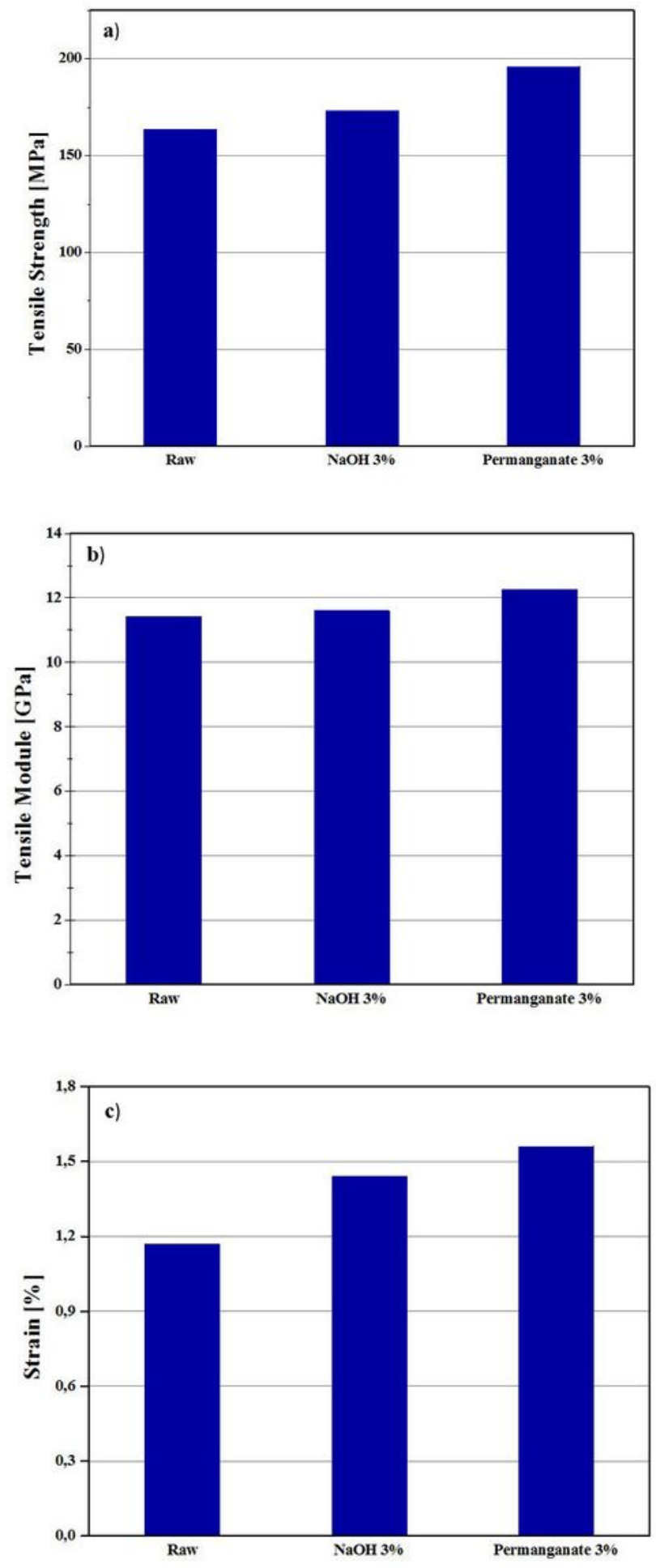

Figure 11

Tensile properties of tensile strength (a), tensile modulus (b) and strain at break (c) of RIVF, A-IVF and PIVF 


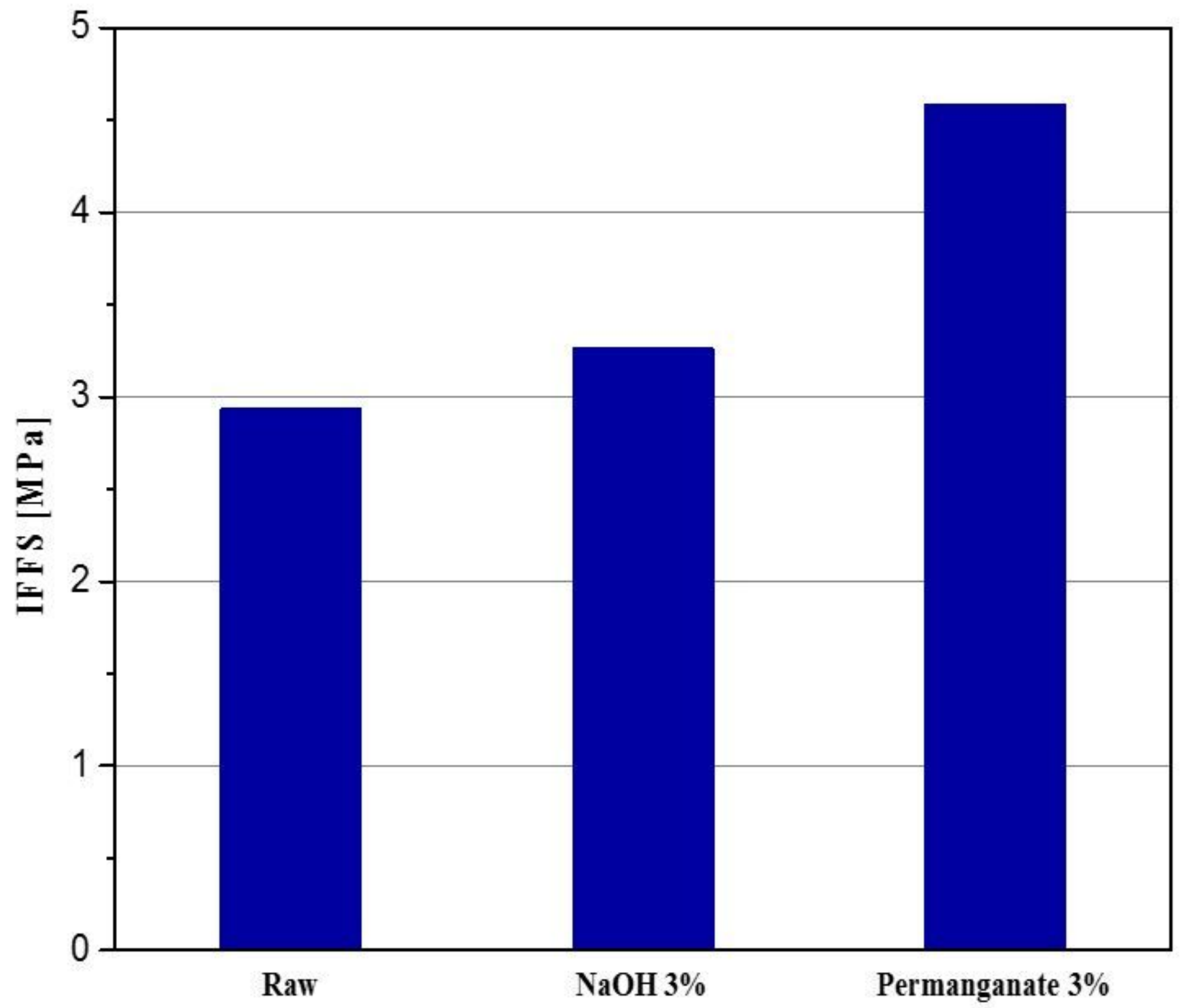

Figure 12

The IFFS properties of R-IVF, A-IVF and P-IVF. 